\title{
TyPeS OF MEMORY CODES IN IMMEDIATE SERIAL VERBAL RECALL OF ARABIC: INVESTIGATION OF PhONOLOGiCAL AND Visual Similarity EFFECTS
}

\author{
By \\ Dr. Hanaa Ezzat Mohamed Abdelgawwad Hussein \\ Lecturer of Educational Psychology, Faculty of Education, \\ Fayoum University ,Egypt
}

مجلة الدراسات التربوية والاساثية ـ كلية التربية - جامعة دمنهور

المجلد الخامس العدد (3) لسنة 2013 
Types of Memory Codes in Immediate Serial Verbal Recall of Arabic: Investigation of Phonological and Visual Similarity Effects

\section{Dr. Hanaa Ezzat Mohamed}

\section{Abstract}

The study aims at exploring the role of the phonological and visual codes in temporary serial recall of Arabic letters .Native speakers of Arabic were asked to recall four lists of letters which varied in their degree of visual and phonological similarity. Results indicated effect of visual and phonological similarity on immediate serial recall. The results not only confirm phonological encoding to be a basic process in shortterm recall of verbal stimuli in a language other than English, but also lend support to the growing evidence of visual encoding in short-term memory. Results were discussed in the light of the working memory model, and Arabic language orthography. 


\section{مستخلص}

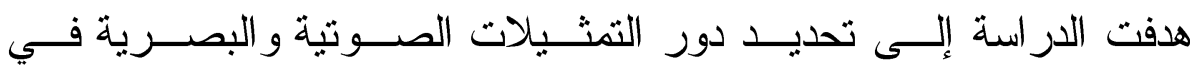

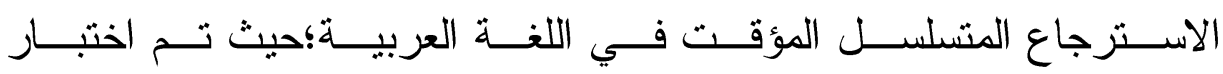

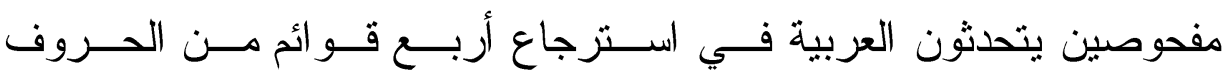

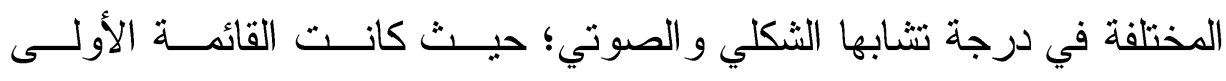

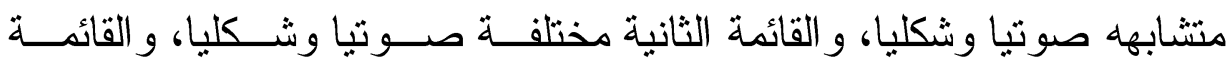

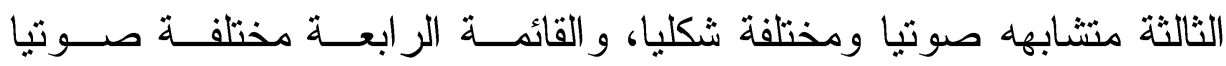

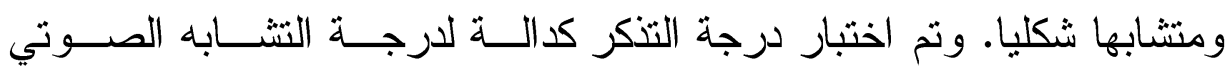

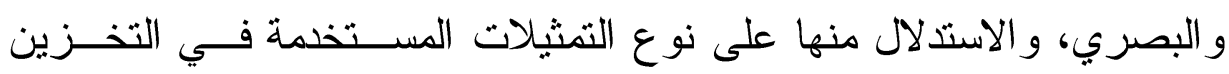

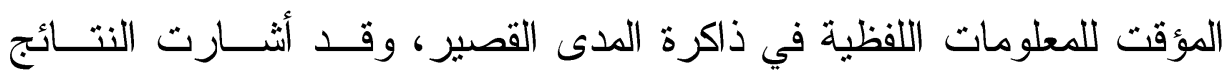

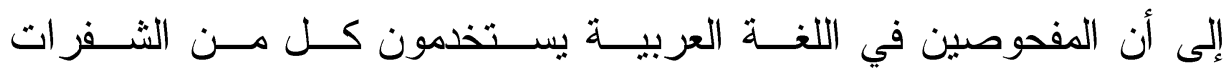

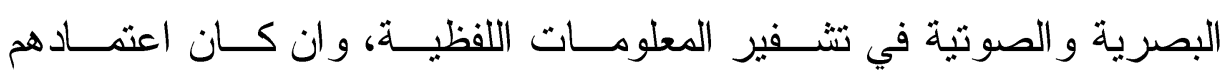

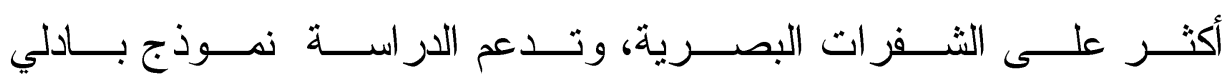
Baddeley

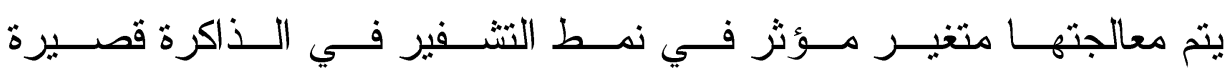

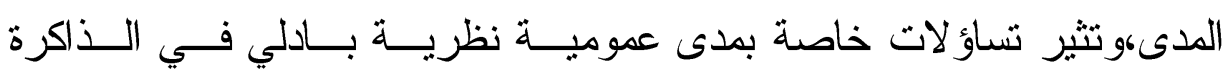

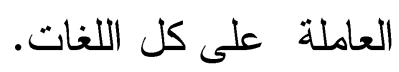




\section{Types of Memory Codes in Immediate Serial} Verbal Recall of Arabic: Investigation of Phonological and Visual Similarity Effects ${ }^{1}$,

A central concern of many studies which employed verbal serial recall was the type of memory coding or representations employed in the retention of verbal information in short term memory. It is well documented in English that in immediate serial recall people employ phonological code in the retention of verbal information in short term memory. The evidence came from the findings of the Phonological Similarity Effect phenomena (PSE) which means that recall of phonologically similar items such as (set, net, pet) are remembered less well than phonologically dissimilar items such as (rat, son, pin ). For example, Drewnowsk, (1980) compared immediate serial recall of phonological rhyming words and dissimilar lists. He reported evidence of better recall for dissimilar words. The result also was replicated by Coltheart (1993) who compared immediate serial recall of visually presented lists that were either phonologically similar or phonologically dissimilar. Recall was better for the dissimilar than for the similar lists in terms of both the strict serial and item recall measures. Poirier

\section{${ }^{1}$ Acknowledgements}

The author is grateful to Professor Alan Baddeley, York University for inspiring her with this research trend, for valuable discussions about the present work, for providing her with articles and books, and for revising the computer experiment before administration during her sabbatical in the Working Memory Unit in York University. Prof Baddeley also reviewed the first write-up of this manuscript and provided helpful comments. 
and Saint-Aubin (1996) reported similar results when comparing serial recall of phonologically rhyming and dissimilar words. Moreover, Macnamara, Moore \& Conard (2011) found phonological similarity effect in simple word span tasks.

Other evidences for the use of phonological code in retaining information in short term memory came from the finding that controlling the role of short term memory in recalling information from long term memory would lead to the disappearance of the phonological similarity effect (Baddeley, Chincotta, Stafford, Turk, 2003). There was also evidence for phonological code from studies which found similar errors committed by participants in recalling verbal information and in spontaneous speech production, suggesting a common verbal mechanism for both kind of verbal tasks (Page, Madge, Cumming, \& Norris, 2007).

Based on similar findings, the working memory model was developed (Baddeley \&Hitch, 1974 cited in Baddeley,1996, 2000, Baddeley,\& Hitch2010), which comprises an executive manager and two slave systems: the verbal short term memory (the phonological loop) and the visual-spatial sketchpad, or the visual memory). It was suggested the phonological loop consists of two subcomponents: a passive store and an active articulatory rehearsal system. It was also assumed that the verbal short term memory (phonological loop) mediates language tasks including verbal recall. The PSE phenomena was accounted for by the existence of the verbal -short term memory and that PSE arises as a result of interference between similar phonological memory traces in the phonological store when the person employs phonological codes (Gathercole \& Baddeley,1993)

The theoretical ideas of the operation of the phonological loop had also been proven in investigation which found evidence of PSE in languages other than English. In Kanji, for example, Saito, Logie, Mia, Law (2005) examined serial 
recall of visually presented items varied in their visually and phonological similarity. It was found that participants were using phonological codes in serial recalling of Kanji as there was strong effect of phonological similarity .Under suppression condition the phonological similarity effect disappeared. Also in Chinese, Li Xyan \& Liu-Si-YUN (2012) examined serial recall of Chinese characters and found evidence of phonological similarity effect.

Other investigation indicated, however, that there are other variables which might affect the occurrence of PSE in serial recall, contradicting the main assumption of the working memory model. For example, some studies provided evidence that phonological similarity might have no effect on immediate serial recall when the items were rhyming and that it might even facilitate immediate item recall (e.g., Fallon, Groves, \&Tehan, 1999, Experiment 1, Macnmara et al ,2011, Experiment 2,3). Fallon et al(1999) performed two experiments to test their hypothesis about positive similarity effect when employing rhyming lists, and found that employing rhyming lists lead to better recall than dissimilar items. Macnmara et al (2011) also reported positive similarity effect in recalling rhyming lists in complex span task .They suggested that "phonological similarity, when operationalized using words that rhyme, serves as a list retrieval cue" which facilitate recall. Lobely, Baddeley, Gathercol (2005) suggested that similarity effect disappeared in rhyming items because participants might be encoding only the initial distinctive parts of the words and thus avoiding the phonological similarity of the items.

Furthermore, Gupta, Lipinksi,\& Aktunc (2005) hypothesized that the level or degree of phonological similarity is another variable which might affect whether PSE is obtained or not. They explained Fallon et al (1999) results as due to that the rhyming lists were more similar than the non rhyming lists. They investigated similarity effect using 
many levels of phonological overlap: rhyming, alliterative, and similar non rhyming/non alliterative. They suggested that rhyming provide a category cuing advantage for item recall which might offset the negative effect of similarity on order information. Thus, it was assumed that if the similarity was in rhyming, the phonological similarity might disappear and rather, its effect might be positive. They found that item recall were higher for rhyming than alliterative and higher for alliterative than similar none rhyming and non alliterative lists. They also found that the recall for similar rhyming lists were better than dissimilar lists even in typical serial recall tasks providing a direct reversal of the classic PSE. The results were obtained for lists of two syllable words as well as for one syllable words providing a clear reversal of the well documented PSE. Gupta et .al suggested that their finding "supported the conclusion that phonological similarity affects immediate serial recall, but the effect is not always negative and thus the treatment of phonological coding in the working memory model needs to be extended and clarified without contradicting its central conclusion"p.1011).

Another variable which has been found to relate to PSE occurrence is the time of retention. For example, Fournet, Juphard , Monnier , Roulin (2003) investigated the effect of retention interval on phonological similarity effect in three paradigms: order reconstruction, serial recall, and free recall. They found that phonological similarity effect only appeared in the two second retention tasks and disappeared in the " 8 " second retention tasks. Moreover, they found that phonological similarity produced better performance when the retention time was " 24 " seconds.

In Sum, taken together the issue of the phonological code role in the retention of verbal of information still remains unresolved. The main assumption of the working memory model is that phonological code -as evidenced by the appearance of phonological similarity effect- is the main code 
for immediate serial recall of verbal information. However, some investigations suggested that phonological similarity has to be taken along with other variables such as the type of phonological similarity, the category cue which are the commonalities between the items, the time of retention, the language orthography characteristics. The question remains: do speakers o Arabic employ phonological code in recalling verbal serial information?

On the other hand, the working memory model (Baddeley,1986; Baddeley 2000) assumes that the phonological loop mediates language tasks including verbal recall, while the visuo-spatial scketch pad mediates visual and motor control tasks (Logie, 1995; Gathercole, Service, Hitch, Adams, \& Martin, 1999b cited in lobly et al , 2005). However, some studies conducted in English provided evidence about visual system in verbal recall tasks. The assumption was validated in studies which found visual similarity effect in recalling verbal information (see Logie, Sala, Wynn, Baddeley,2000 for a review of these studies). However, the visual similarity effect in English studies was related sometimes to the type of letters (capital or small). For example, Walker, Hitch, and Duroe (1993) found evidence of visual similarity effect in three experiments about the capacity of STM retention of several visual small letters items. The appearance of visual similarity effect suggests that visual short term memory can retain many verbal items .However; they found a recency effect in recall of capital items which imply that short-term memory is limited to a single item. The different findings of the studies conducted in English, with small and capital letters, may suggest that visual code may be used under certain circumstances, one of which is distinctive orthography system. So it might be assumed that studies in languages other than English such as Arabic might reach different conclusions regarding visual code role in verbal 
serial recall, and that might suggest that codes used in recalling information are language sensitive.

Investigation of visual coding in other languages found contradictory results. For example in Kanji language, Saito et al (2005) reached similar conclusion to that of English studies when they examined serial recall of visually kanji characters and they found that participants were employing phonological and visual coding in retaining verbal information in STM. It was also found that the two codes are working independently as the phonological similarity effect disappeared under suppression condition. In an early Chinese study by Hue \&Ericsson (1988) visual similarity effect with long display of Chinese characters was reported (cited in Logie et al, 2000). However, Li Xyan \& Liu Si-Yun (2012) -who examined types of memory codes in Chinese- reached different conclusion regarding the visual similarity effect. They found evidence of interaction between phonological and visual similarity effect as visual similarity improved the recall of phonological similar items while they eliminated the recall of the dissimilar ones. They conducted another experiment and found both a phonological similarity effect and a reversed visual similarity effect. They concluded that that their results were related to Chinese language characteristics.

Thus, the question remains as to when the visual code is working and how it interacts with the phonological codes. Logie and his colleagues (2000) conducted four experiments to test the use of visual system in retaining verbal information. They presented their subjects with sets of letters and words that varied in their visual similarity under suppression and no suppression condition and asked them to recall the items in the same order. It was found that there was evidence of visual similarity and phonological similarity effect which means that participants were using visual and phonological codes in recall of verbal information from short term memory. They repeated the experiment using letters 
instead of words and found visual similarity effect especially under articulatory suppression condition .They concluded that their participants used visual codes in retaining information when they fail to use the phonological codes as is the case in the articulatory suppression condition. However, one problem of Logie et al study was to find words in English which were visually similar and were not phonologically similar such as FLY, PLY, DRY. So the question needs to be addressed in a study which would use letters instead of words. In other words if there is a visual system for serial recall of verbal information, then that visual similarity effect would appear even if the items are letters.

However, Poirier and her colleagues(2007) provided evidence that visual effect can be used in silent condition when phonological code is available. In their investigation they examined if evidence of visual coding could be provided when the task required the short-term maintenance of a sequence of items that could be encoded verbally or phonologically. They found an evidence of visual similarity effect in three different experiments. The results of these experiments serve to establish that even under conditions in which verbal coding was clearly involved, a reliable visual similarity effect was observed.

\section{- The Current Study Problem:}

In Sum there are so many issues still remain unresolved as to the types of memory codes employed in the retention of verbal of information. Investigation suggested that phonological similarity has to be taken along with other variables such as the type of phonological similarity, the category cue which are the commonalities between the items, the time of retention, the language orthography characteristics(Saito et al , 2005; Gupta et al , 2005, Poirier et al , 2007 ;Fourner et. al, 2003; Macnamra et al ,2011; Li Xyan \&LIU ,2012) . 
Moreover, the issue of the role of visual code in immediate serial recall of verbal information and how it works with phonological code is still unresolved. If there is indeed what Logie et al (2000) called a "temporary passive visual store or a visual cache that stores visually presented items, it might be expected that visual similarity effect would be present with verbal information regardless of type of information or even the orthography characteristics of the language being recalled.

Moreover, while the visual code is documented in many English studies, a reversed visual effect was obtained in one Chinese study (Li Xyan, \&LIU ,2012). To the researcher's knowledge no attempt has been made to investigate the visual and phonological similarity effects in recalling Arabic as an indicator of the types of memory encoding employed in immediate serial verbal recall. The question remains as to what types of memory codes do speakers of Arabic employ in immediate serial verbal recall under no suppression condition?.

The problem of the present investigation was to answer the question of what codes do speakers of Arabic employ in immediate serial verbal recall, through investigating the occurrence of visual and phonological similarity effects in serial recall of verbal information in short retention condition. The finding would shed light in the issue of the universality of the working memory model through comparing the present findings with those obtained from English investigation.

\section{Hypotheses:}

\section{The researcher hypothesized that:}

1) Speakers of Arabic would employ phonological code in immediate serial verbal recall; in other words, phonologically similar items would be remembered less well than phonologically dissimilar items. (Phonological similarity effect would be observed).

2) Speakers of Arabic would employ visual code in immediate serial verbal recall; in other words, visually 
similar items would be remembered less well than visually dissimilar items. (visual similarity effect would be observed).

\section{Method:}

\section{Participants:}

A total of (34) Egyptian adults, aged between 25 and 37 years,(11) of them were enrolled in graduate program, York university, UK and (23 )were from Fayoum University, Egypt. They volunteered to participate in this study. They were all native speakers of Arabic. However, the data collected in England was just used for modifying the experiment and has not been included in the analysis as only data from (20) persons-(mean age 31.4)- from Fayoum university was included.

\section{- Design \& Material:}

The experimental design comprised four sets of six letters for immediate serial recall ${ }^{2}$ : Arabic letters were employed instead of words so as to isolate the effect of lexicality or semantic factors on performance. Also Arabic letters have an advantage which is that some are visually similar and phonologically dissimilar and some are phonologically similar and visually dissimilar. This would help in investigating the interaction between phonological and visual similarity effects as we can make letters sets which varied in their level of phonological and visual similarity effect.

All participants were tested in recalling four sets of letters: phonologically and visually similar (PSDS), phonologically and visually dissimilar (PDVD), phonologically similar and visually dissimilar(PSVD), phonologically dissimilar and visually similar(PDVS). Phonological similarity was defined as whether or not the pronunciation of two letters shared at

\footnotetext{
${ }^{2}$ See appendix (1) for the letter sets.
} 
least one constant and one vowel such the pronunciation of the letters (ض، ص).Visual similarity was defined as having only one distinctive feature between two similar letters forms (ج). Every set of letters was presented eight times in different order giving (48) trials. The experiment was designed by the author using E. Prime program, version 2.

\section{Procedures:}

Participants were examined individually in a quiet room; every participant was informed that he would be presented with four lists of (6) letters. For each sequence there were eight trials (see appendix (1) for the actual sequence used in the experiments. The letter sequence would appear serially. Every letter appeared on a computer display for (1) second, then the letter disappeared and a question mark appeared for another second, and then appeared another letter up till the sequence is all presented. Then the participant was asked to write the letters presented in the same order in a separate sheet. He had to push space for another sequence order to be presented. Then the sequence of letters was presented again, but in different order and the participant was asked to write the letters in the same order again. Then the participant was told that a new group of letters would appear with the same procedures. Between every letter set, a note would appear on the computer that you had finished a list and a new list would appear. 


\section{- Results:}

Each response was scored as correct if it was the correct letter in the correct position. Mean and SD values for the recall in the four conditions are presented in table (1).

Table: (1) Mean and SD Values for the recall in the four recall conditions

\begin{tabular}{|l|l|l|l|l|}
\hline \multirow{2}{*}{ condition } & \multicolumn{2}{|c|}{ Visually similar } & \multicolumn{2}{c|}{ Visually dissimilar } \\
\cline { 2 - 5 } & $\mathrm{M}$ & SD & $\mathrm{M}$ & SD \\
\hline Phonologically similar & 31.55 & 1.34 & 38.5 & 1.05 \\
\hline $\begin{array}{c}\text { Phonologically } \\
\text { dissimilar }\end{array}$ & 34.95 & 1.08 & 38.35 & 1.06 \\
\hline
\end{tabular}

A repeated measures ANOVA, with the letter sets (PSVS, PDVD, PSVD, PDVS) as the within factor variable, revealed that the recall differed statistically significantly between the four lists of letters $(\mathrm{F}(28.047)=, \mathrm{p}<0.001$. Post hoc tests using the Bonferroni correction summarized in table(2) revealed that there was a significant difference in recall between (PSVS) list and (PDVD) list $(\mathrm{P}<0001)$, (PSVS) list and (PSVD) list $(\mathrm{P}<0.01)$, and between recall of (PDVD) list and (PDVS) list $(p<003)$, giving strong evidence of visual similarity effect. Visually similar items were remembered less well than visually dissimilar items.

Moreover, there was statistically significantly difference between (PSVS) list and (PDVS) list $(\mathrm{P}<0.0001)$ giving evidence of phonological similarity effect. Taken together these significant differences show evidence of visual and phonological similarity effects in recalling Arabic letters.

Table:(2) Post hoc comparisons using the Bonferroni correction between the four recall conditions

\begin{tabular}{|c|c|c|c|c|}
\hline \multirow{2}{*}{$\begin{array}{c}(\mathrm{I}) \\
\text { condition }\end{array}$} & $\begin{array}{c}(\mathrm{J}) \\
\text { condition }\end{array}$ & $\begin{array}{c}\text { Mean } \\
\text { Difference (I-J) }\end{array}$ & Std. Error & Sig. $^{{ }^{2}}$ \\
\hline \multirow{3}{*}{ 1(PSVS) } & 2 & $-6.800--^{-*}$ & 1.040 & .000 \\
\cline { 2 - 5 } & 3 & $-6.950-$ & .930 & .000 \\
\cline { 2 - 5 } & 4 & $-3.400-$ & .947 & .012 \\
\hline \multirow{2}{*}{ 2(PDVD) } & 1 & 6.800 & 1.040 & .000 \\
\cline { 2 - 5 } & 3 & $-.150-$ & .886 & 1.000 \\
\cline { 2 - 5 } & 4 & 3.400 & .816 & .003 \\
\hline
\end{tabular}




\begin{tabular}{|c|c|c|c|c|}
\hline \multirow{3}{*}{3 (PSVD) } & 1 & 6.950 & .930 & .000 \\
\cline { 2 - 5 } & 2 & 0.150 & .886 & 1.000 \\
\cline { 2 - 5 } & 4 & 3.550 & .591 & .000 \\
\hline \multirow{3}{*}{$4($ PDVS) } & 1 & $3.400^{*}$ & .947 & .012 \\
\cline { 2 - 5 } & 2 & $-3.400-^{*}$ & .816 & .003 \\
\cline { 2 - 5 } & 3 & $-3.550-^{*}$ & .591 & .000 \\
\hline
\end{tabular}

Finally there was statistically significantly difference between (PSVD) list and (PDVS) list $(\mathrm{p}<0.0001)$, but no significant difference between recall of (PDVD) list and (PSVD) list, which implies that visual code is more important than phonological code in recalling Arabic. From the Mean Difference we can see that recall was reduced when the items were either phonologically or visually similar, while recall was at its highest level when the items were visually dissimilar regardless of the phonologically similarity of the items. Also phonological similarity had a negative effect on performance when the items were visually similar, but that effect was not observed when the items were visually distinctive. We can therefore conclude that recall of phonologically similar letters were poorer than dissimilar letters when the items were visually similar. Also there was an evidence of a strong visual similarity effect which appeared when the lists included phonologically similar or dissimilar items. 


\section{- Discussion}

The experiment reported here manipulates phonological and visual similarity to determine the types of memory codes or representations employed by people in immediate recall of verbal information. Letters were used to avoid semantic features contribution to recall. Also the characteristics of Arabic orthography allowed the researcher to compose lists of letters which varied in their level of phonological and visual similarity. Recall of four sets of letters were compared as a function of the level of visual and phonological similarity (1-PSVS, 2-PDVD, 3-PSVD, 4-PDVS). Visual similarity effect along with a phonologically similarity effect were obtained.

In Arabic-as hypothesized- the classical phonological similarity effect reported in literature was observed (Coltheart 1993; Logie et. al, 2000, Saito et. al, 2008; Macnamra et. al, 2011), which implies that phonological similarity immediate serial recall, providing evidence that the code used in verbal short term memory is phonological in nature. This result is, thus, consistent with the account of phonological similarity effect given within the working memory model (e.g. Baddeley 1986, 1996, 2000; Baddeley et. al, 1998; Baddeley et. al, 2003; Baddeley \& Hitch, 2010).

An important finding of this study was the appearance of a strong visual similarity effect in verbal serial recall of Arabic, supporting hypothesis (2). This result is similar to those of Logie et al (2000) who found evidence of visual similarity effect when recalling words and letters especially under suppression condition, and Saito et al (2005) study in recalling kanji items. However, the finding reported here did not support the conclusions of Logie and his colleagues that visual codes should only appear under articulatory suppression condition. Visual similarity effect was observed in the current study under no suppression condition and regardless of the phonological similarity of the 
items, while the phonological similarity effect was observed only when the items were visually similar. In other words, visual code was used even when phonological code was available. The result builds upon the findings of Poirier et al (2007) who found evidence of poor recall of visual items under both silent and articulatory suppression condition and when the items were phonologically distinctive

One explanation for participants' preference to use visual code in recalling in the current experiment was that the time of displaying the information was one second, as some studies found evidence of a visual code in recalling of letters in short display time (see Logie et al, 2000 for a review of theses studies).

Moreover the finding that visual code is more important than phonological code in recalling Arabic- as evidenced by absence of recall difference between the PSVD list and the PDVD- might be explained in the light of the type of phonological similarity employed in the experiment. The PSVD list comprised letters which had similar rhyme. Previous investigations indicated that memory for rhyming words were superior than the non rhyming(Fallon et al ,1999; Macnamra et al , 2011) as the participants might be encoding only the initial part of the name of the letter, making the phonologically similar letters distinctive(Lobely et al , 2005,p.1464). Or the rhyme might have acted as a retrieval cue" or a category cue which eliminated the phonological similarity effect (Macnamra et al, 2011 ). So the Arabic orthography with its rhyming letters might have eliminated the negative effect of phonological similarity on recall and triggered the use of visual features as a representation in the immediate short term memory.

The study, then, replies the question raised by Logie and his colleagues (2000) of whether visual effect reflects general characteristics of serial recall. Moreover, the observed visual similarity effect supports the argument about the existence of 
what Logie et. al called" a visual cache" for coding verbal information as even under condition in which verbal coding is possible, participants used visual representations. The suggestion is confirmed by the fact that the best performance was when the items were visually distinctive regardless of phonological similarity. The study also replied the question of the universality of the working memory model as the pattern of results of this study was consistent with the main concepts of the working model( Baddeley,2000; Baddeley \&Hitch,2010) and supports the co existence of a separate visual system or short term store in addition to phonological representation for storing sequential verbal information when presented. However, the use of visual similarity effect indicated that the nature of the representations supporting the verbal short term memory in Arabic are more complex than it is thought in the working memory model.

Finally our finding provided evidence about the effect of language orthography on the code used in recalling. It is the first study-to the researcher's knowledge-which found that visual code is more important than phonological code. This might be related to the visually distinctive features of the Arabic letters which make it easier for participants to retain them visually.

Future investigation should use word and nonword lists which differ in their level of visual and phonological similarity levels (rhyming, alliterative at the beginning or end of the word) to replicate these findings. More studies in Arabic languages are also encouraged. The question remains as to are working memory models universal and can account for recall in different orthographies

\section{- Educational Implication}

Implication for the current study finding is that presentation of verbal information in Arabic should be visually as that will lead to better retention and recall of information in short term memory. Teachers while presenting 
information to Arabic students should use visual aids more than verbal aids.

Also even in training verbal tasks, visual memory training should be emphasized as visual system is also employed in retaining verbal information. Thus in training translation, reading comprehension or other verbal tasks, teachers should also enhance the visual system by visual tasks. 


\section{References:}

1) Baddeley, A. D. (1986). Working memory. New York: Oxford University Press.

2) Baddeley, A. D. (1996). Exploring the central executive.Quarterly Journal of Experimental Psychology, 49A28 - 5

3) Baddeley, A. D. (2000). The episodic buffer: A new component of working memory? Trends in Cognitive Neuroscience, 11, 417-423.

4) Baddeley, A. D. , Chincotta, D. , Stafford, L., Turk, D. (2003). Is the word length effect in STM entirely attributable to output delay? Evidence from serial recognition. Quarterly Journal of Experimental Psychology, 55A, 353-369.

5) Baddeley, A. D. , Gathercole, S. E. , \& Papagno, C. (1998). The phonological loop as a language learning device. Psychological Review, 105, 158-173.

6) Baddeley, A .D. , Hitch, G. (2010). The multi-component model of working memory. Scholarpedia, 5(2): 3015, http:// www. Scholarpedia. Org / article/ Working memory

7) Coltheart, V. (1993). Effects of phonological similarity and concurrent irrelevant articulation on short-term memory recall of repeated and novel word lists. Memory and Cognition, 21, 539-545.

8) Drewnowski, A. (1980). Attributes and priorities in shortterm recall: A new model of memory span. Journal of Experimental Psychology: General, 109, 208-250.

9) Fallon, A. B. , Groves, K. , \& Tehan, G. (1999). Phonological similarity and trace 
degradation in the serial recall task: When CAT helps RAT, but not MAN. International Journal of Psychology, 34, 301-307.

10) Fournet, N. , Juphard, A. , Monnier, C. „\& Luc Roulin, J.(2003). Phonological similarity in free and serial recall: The effect of increasing retention intervals, International Journal of Psychology, 38(6), 384-389.

11) Gathercole, S. E. , \& Baddeley, A. D. (1993). Working memory and language. Hove, UK: Lawrence Erlbaum Associates Ltd

12) Gupta, P. , Lipinksi, J. , \& Aktunc, E. (2005). Reexamining the phonological similarity effect in immediate serial recall: The roles of type of similarity, category cuing, and item recall. Memory \& Cognition, 33, 1001-1016.

13) Lobely, Baddeley, Gathercole, S. E. (2005). Phonological similarity effects in verbal complex span, The Quarterly Journal of Experimental Psychology, 58A (8), 1462-1478.

14) Logie, R, H. , Sala, S, D., Wynn, V. , Baddeley, A. D.(2000). Visual similarity effects in immediate verbal serial recall, The Quarterly Journal of Experimental Psychology, 53A (3), 626-646.

15) LI Xuan . , LIU Si- Yun. (2012). The Effects of phonological similarity and visual similarity in immediate serial recall of Chinese characters [J]. Acta Psychologica Sinica, 2012, 44 (12): 1571-1582. http://118.145.16.229:81/ Jweb_xlxb/ EN/10.3724/SP.J.1041.2012.01571 
16) Macnamara, B, N., Moore, A. B., Conway, A. R.(2011). Phonological similarity effects in simple and complex span tasks. Memory \& Cognition, 39(7), 1174-1186, DOI 10.3758/s13421-011-0100-5

17) Page, M., Madge, A., Cumming, N., \& Norris, D. (2007). Speech errors and the phonological similarity effect in short-term memory: evidence suggesting a common locus. Journal of Memory and Language, 56, 49-64.

18) Poirier, M., \& Saint-Aubin, J. (1996). Immediate serial recall, word frequency, item identity, and item position. Canadian Journal of Experimental Psychology, 50, 408-412.

19) Poirier, M., \& Saint-Aubin, J. , Elwhite, K. M., Mohanadas, T., \& Mahammed ,G.(2007). Visual similarity effects on short-term memory for order: The case of verbally labeled pictorial stimuli: Memory \& Cognition, 35 (4), 711-723.

20) Saito, S., Logie, H. R. , Mia, A. , \&Law, A. (2008). Visual \&Phonological similarity effect in verbal immediate serial recall: A test with Kanji materials, Journal of Memory \& Cognition, 59(1). DOI: 10.1016/j.jml.2008.01.004 
21) Appendix (1)

Letters Sets Order of Presentation

\begin{tabular}{|c|c|c|c|c|c|c|}
\hline $\operatorname{Set}(1)$ & \multicolumn{6}{|c|}{$\begin{array}{l}\text { (PSVS),Phonologically and } \\
\text { Visually Similar }\end{array}$} \\
\hline 1 & ض & S & $\varepsilon$ & د & $\dot{j}$ & $\dot{\varepsilon}$ \\
\hline 2 & ض & $\varepsilon$ & $\dot{j}$ & I & $\varepsilon$ & ص \\
\hline 3 & ص & $\dot{\varepsilon}$ & $\dot{j}$ & د & $\varepsilon$ & ض \\
\hline 4 & $j$ & 4 & ض & $\dot{\varepsilon}$ & $\varepsilon$ & د \\
\hline 5 & $\dot{\varepsilon}$ & $\varepsilon$ & د & ص & ض & $\dot{j}$ \\
\hline 6 & ض & $\varepsilon$ & د & ص & $\dot{j}$ & $\dot{\varepsilon}$ \\
\hline 7 & ض & נ & ص & $\dot{j}$ & $\varepsilon$ & $\dot{\dot{\varepsilon}}$ \\
\hline 8 & $\dot{j}$ & ב ב & ض & $\dot{\varepsilon}$ & ص & $\varepsilon$ \\
\hline $\operatorname{Set}(2)$ & \multicolumn{6}{|c|}{$\begin{array}{l}\text { (PDVD, Phonologically and } \\
\text { Visually Dissimilar }\end{array}$} \\
\hline 1 & J & ظ & ق & ج & $\dot{ن}$ & سـ \\
\hline 2 & سـ & ج & ق & ظ & J & $\dot{~}$ \\
\hline 3 & ق & 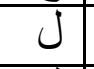 & b & $\dot{ن}$ & سـ & ج \\
\hline 4 & ن & J & سـ & ظ & ج & ق \\
\hline 5 & ظ & ق & ج & سـ & J & $\dot{~ ن}$ \\
\hline 6 & ن & ق & سـ & ظ & ج & $J$ \\
\hline 7 & ج & ظ & ن & ق & سـ & $J$ \\
\hline 8 & J & 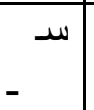 & ق & ن & ظ & ج \\
\hline $\operatorname{Ser}(3)$ & \multicolumn{6}{|c|}{$\begin{array}{l}\text { (PSVD: Phonologically Similar } \\
\text {,but Visually Dissimilar }\end{array}$} \\
\hline 1 & س & $\varepsilon$ & هـ & ب ب & P & ج \\
\hline 2 & 5 & $\varepsilon$ & ب ب & $ه$ & س & ج \\
\hline 3 & $\varepsilon$ & س & $\rightarrow$ & ب ب & ج & 5 \\
\hline 4 & 5 & ج & $\varepsilon$ & س & $\rightarrow$ & ب \\
\hline 5 & ب & $\rightarrow$ & س & $\varepsilon$ & ج & 5 \\
\hline 6 & 5 & ب & $\rightarrow$ & س & ج & $\varepsilon$ \\
\hline 7 & ج & س & $\rightarrow$ & ب & $\varepsilon$ & 5 \\
\hline 8 & ج & 5 & ب & $\rightarrow$ & $\varepsilon$ & س \\
\hline $\operatorname{Set}(4)$ & $(\mathrm{P}$ & \multicolumn{5}{|c|}{ Phonologically Dissimilar } \\
\hline
\end{tabular}

doi: 10.12816/0001299 
مجلة الدراسات الثربوية و الاسانية ـ كلية التربية ـ جامعة دمنهور -المجلا الخامس العدد (3) لسنة 2013

\begin{tabular}{|c|c|c|c|c|c|c|}
\hline & DVS & and & $\mathbf{s u}$ & $\mathbf{S i}$ & & \\
\hline 1 & صـ & b & j & J & $\tau$ & ج \\
\hline 2 & b & صـ & J & $j$ & $\tau$ & ج \\
\hline 3 & صد & $b$ & 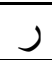 & ج & $\tau$ & j \\
\hline 4 & j & b & $\tau$ & ج & صـ & $J$ \\
\hline 5 & صـ & ج & $\tau$ & $J$ & $b$ & j \\
\hline 6 & ج & $j$ & $\tau$ & $J$ & صد & $b$ \\
\hline 7 & $b$ & $j$ & $J$ & صد & $\tau$ & ج \\
\hline 8 & b & صـ & ج & J & $j$ & $\tau$ \\
\hline
\end{tabular}


